\title{
Simple spectrophotometric methods for the determination of amlodipine and atorvastatin in bulk and tablets
}

\author{
Imad Osman Abu Reid ${ }^{1 *}$, Hind Mohamed Farid ${ }^{2}$ and Sara Osman Eltayeb ${ }^{2}$
}

\begin{abstract}
Background: Simultaneous spectrophotometric determination of samples containing more than one analyte presents analytical challenge; the choice of an analytical procedure is strictly related to the extent of overlapping between the individual absorption peaks of these components; if the absorption peaks are satisfactorily resolved, the determination is not problematic, but if the individual component signals are partly or totally overlapped, then powerful techniques are needed. Combined amlodipine and atorvastatin are typical example where special techniques are needed to resolve bands overlapping.

Results: Application of multiwavelength regression and absorbance factor methods to the analysis of atorvastatin and amlodipine combination proved to be satisfactorily capable of accurate and precise determination of the two analytes. The two methods recoveries were very close to the expected analytes concentrations, and the precision of the methods was $<2 \%$ relative standard deviation. Statistical comparison indicated that there is no significant difference between the assay results obtained by the two method as the calculated $t$ values 0.91 and 1.13 for amlodipine and atorvastatin, respectively, were less than the tabulated $t$ value 2.23 at $95 \%$ confidence level.
\end{abstract}

Conclusion: The proposed methods are accurate, precise, simple and inexpensive. They can be applied successfully to the analysis of the two drugs in combined dosage form.

Keywords: Multiwavelength regression, Absorbance factor, Atorvastatin, Amlodipine, Spectrophotometry

\section{Background}

Amlodipine (AML), chemically, is 3-O-Ethyl5-O-methyl 2-(2-aminoethoxymethyl)-4-(2-chloro-phenyl)-6-methyl-1,4-dihydropyridine-3,5 dicarboxylate (Fig. 1a). It has been used in the management of hypertension as it blocks calcium ions transmembrane influx into vascular smooth muscles and cardiac smooth muscles [1].

Atorvastatin (AVS), chemically, is $\left[R-\left(R^{*}, R^{*}\right)\right]-2-(4-$ Fluorophenyl)-b,d-dihydroxy-5-(1-methyl-ethyl)-3-phenyl-4-[(phenylamino)carbonyl]-1H-pyrrole-1 heptanoic acid (Fig. 1b). It has been used as a lipid-lowering agent

\footnotetext{
*Correspondence: iabureid@hotmail.com

1 Department of Pharmaceutical Chemistry, Faculty of Pharmacy,

University of Khartoum, P.O. Box 1996, Khartoum, Sudan

Full list of author information is available at the end of the article
}

as it inhibits the conversion of HMG-CoA to mevalonic acid a rate limiting step in hepatic cholesterol production [2].

The combination of AML and AVS as antihypertensive and lipid-lowering medications clinically used to reduce the risk of coronary artery disease, stroke and death in patients with cardiovascular risk factors [3].

The simultaneous determination of amlodipine besylate and atorvastatin calcium combination as tablets dosage form is not yet official in any compendia; however, literature survey revealed that there are several reported methods, using analytical techniques such as chromatography, spectrophotometry, spectrofluorimetry, electrochemistry and chemometry for the simultaneous determination of AML and AVS in binary mixtures [4-29]. 


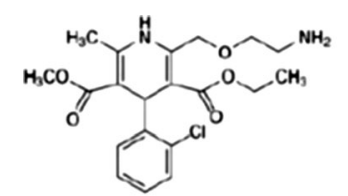

(a)

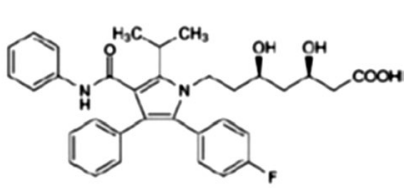

(b)
Fig. 1 Chemical structure of $\mathbf{a}$ amlodipine and $\mathbf{b}$ atorvastatin

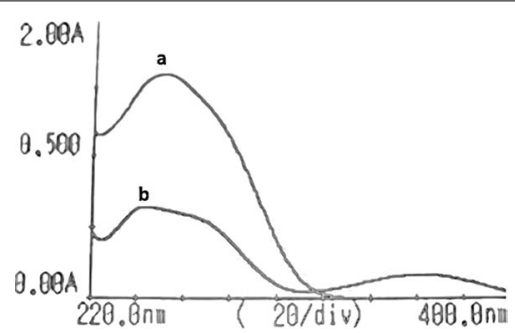

Fig. 2 Overlay absorbance spectra of a atorvastatin $(20 \mu \mathrm{g} / \mathrm{mL})$ and b amlodipine $(7.5 \mu \mathrm{g} / \mathrm{mL})$ in $50 \%$ aqueous methanol

Amlodipine and atorvastatin absorbance spectra (Fig. 2) showed extensive overlapping in the region of 220-300 nm, and resolution of these overlapping spectra and subsequent determination of the analytes concentrations in combined dosage forms is only possible if more sophisticated and expensive techniques are used. The objective of this work was to use multiwavelength regression analysis [30] and absorbance factor method [31] as simple, inexpensive, and reliable UV-spectrophotometric methods in place of expensive techniques based on separation or sophisticated methods using specialized computer programs.

\section{Theoretical background}

\section{Multiwavelength regression analysis}

Assuming additivity of absorbance and validity of Lambert-Beer's law, the absorbance of a mixture is the sum of the absorbance values of its individual components.

If we have a mixture consisting of two components, 1 and 2 , with an unknown concentration of $C_{1}$ and $C_{2}$, then absorbance of the unknown mixture,

$$
A_{\text {mixture }}=A_{1}+A_{2}
$$

applying Beer's law: $A_{1}=\varepsilon_{1} b C_{1}$ and $A_{2}=\varepsilon_{2} b C_{2}$.

Substituting:

$$
A_{\text {mixture }}=\varepsilon_{1} b C_{1}+\varepsilon_{2} b C_{2} .
$$

However, the absorbencies of standard solutions of the same substances will follow the same Beer's law relationship and have the same molar absorbance, $\varepsilon$, and one centimeter path length, $b$, as the unknown solutions under the same conditions.

Therefore, we can write:

$$
A_{\text {standard } 1}=\varepsilon_{1} b C_{\text {standard } 1} \text { and } A_{\text {standard 2 }}=\varepsilon_{1} b C_{\text {standard } 2}
$$

Rearranging these relationships:

$$
\begin{aligned}
& \varepsilon_{1} b=A_{\text {standard } 1} / C_{\text {standard } 1} \text { and } \\
& \varepsilon_{2} b=A_{\text {standard } 2} / C_{\text {standard } 2}
\end{aligned}
$$

Substituting,

$$
\begin{aligned}
A_{\text {mixture }}= & A_{\text {standard 1 }} / C_{\text {standard } 1} C_{1}+A_{\text {standard } 2} \\
& +A_{\text {standard } 2} / C_{\text {standard }} \cdot C_{2}
\end{aligned}
$$

or

$$
\begin{aligned}
A_{\text {mixture }}= & C_{1} / C_{\text {standard } 1} \cdot A_{\text {standard } 1} \\
& +C_{2} / C_{\text {standard } 2} \cdot A_{\text {standard } 2}
\end{aligned}
$$

Dividing by $A_{\text {standard } 1}$ and simplifying we obtain:

$$
\begin{aligned}
A_{\text {mixture }} / C_{\text {standard 1 }}= & C_{1} / C_{\text {standard 1 }}+C_{2} / C_{\text {standard 2 }} \text {. } \\
& A_{\text {standard 2 }} / A_{\text {standard } 1}
\end{aligned}
$$

Therefore, a plot of

$$
A_{\text {mixture }} / C_{\text {standard 1 }} \text { versus } A_{\text {standard 2 }} / A_{\text {standard(2) }}
$$

will give

$$
\text { slope }=C_{2} / C_{\text {standard } 2} \text { and intercept } C_{1} / C_{\text {standard } 1}
$$

That is, the concentration of the unknown component 2 $\left(C_{2}\right)$ in the mixture equals the slope times the concentration of the standard solution for component 2. Likewise, the concentration of the unknown component $1\left(C_{1}\right)$ in the mixture equals the product of the intercept times the concentration of the standard solution for component 1 or simply

$$
C_{1}=\text { intercept } \times C_{\text {standard } 1}
$$

and

$$
C_{2}=\text { slope } \times C_{\text {standard } 2}
$$

\section{Absorption factor method}

The method depends on the fact that in the overlapping spectra of a mixture of two drugs, e.g., $X$ and $Y, X$ has some interference at $\lambda_{\max }$ of $Y\left(\lambda_{1}\right)$ and has no absorption at another wavelength $\left(\lambda_{2}\right)$ that $Y$ show absorbance at $\lambda_{1}$; the absorbance of the mixture at $\left(\lambda_{2}\right)$ equals the absorbance of $Y$.

Absorbance of $Y$ at $\lambda_{1}=\left(\operatorname{abs} Y_{\lambda 1} /\right.$ abs $\left.Y_{\lambda 2}\right)$. abs $\lambda_{22}(X+Y)$ 
Absorbance of $X$ at $\lambda_{1}=\operatorname{abs}_{\lambda 2}(X+Y)-\left(\right.$ abs $Y_{\lambda_{1}} /$ abs $\left.Y_{\lambda 2}\right)$. abs $\lambda_{22}(X+Y)$

The proposed methods allow accurate and precise determination of binary mixtures of compounds with highly overlapped spectra using simple and easy mathematics instead of more complex mathematical procedures.

\section{Methods}

\section{Materials and reagents}

Amlodipine besylate and atorvastatin calcium working standards were supplied by Amipharma Pharmaceutical Industries-Sudan and Methanol from Carlo Erba-Italy.

Lorvast plus tablets manufactured by Tabuk Pharmaceuticals-Sudan labeled to contain $20 \mathrm{mg}$ of Atorvastatin as calcium and $5 \mathrm{mg}$ of Amlodipine as besylate and were purchased from the local market.

The diluent (50\% v/v aqueous methanol) was prepared by mixing equal volumes of methanol and distilled water.

\section{Instrument and software}

A double beam UV/Vis spectrophotometer, Shimadzu UV-1800, was employed with a matching pair of $1 \mathrm{~cm}$ quartz cells for all analytical work. Microsoft Excel Spreadsheet 2013 was used for data analysis.

\section{Standards stock solutions}

Accurately weighed about $15 \mathrm{mg}$ Amlodipine besylate and $25 \mathrm{mg}$ atorvastatin calcium working standard were separately weighed and transferred into separate $100 \mathrm{~mL}$ volumetric flasks, dissolved using the diluent and the volumes were completed to the mark using the diluent.

\section{Calibration curves}

Aliquot volumes $(1-5 \mathrm{~mL})$ from each stock solution were transferred into two separate sets of five different $50 \mathrm{~mL}$ volumetric flasks and made to mark with the diluent to give amlodipine in the range of $2-10 \mu \mathrm{g} / \mathrm{mL}$ and atorvastatin in the range of $4-20 \mu \mathrm{g} / \mathrm{mL}$. The absorbance of these solutions was measured at the wavelengths selected for each method, and the linear regression parameters were obtained for the absorbance values against their corresponding concentrations.

\section{Preparation of synthetic mixtures}

Six laboratory synthetic mixtures containing different concentrations of amlodipine and atorvastatin were prepared by mixing different volumes from the two stock solutions in six separate $50 \mathrm{~mL}$ volumetric flask and making the volume to the mark with the diluent.

\section{Preparation of analytical standards (multiwavelength regression method)}

From each analyte, standard stock solution $5 \mathrm{~mL}$ were transferred into a separate $50 \mathrm{~mL}$ volumetric flasks and made to mark with the diluent.

\section{Sample preparation}

Twenty tablets were accurately weighed and crushed to a fine powder; the weight of powder equivalent to one tablet was transferred into a $100 \mathrm{~mL}$ volumetric flask, dissolved with the diluent, sonicated for $15 \mathrm{~min}$ and filtered using $0.45 \mu \mathrm{m}$ nylon syringe filter; $5 \mathrm{~mL}$ of the filtrate were diluted to $50 \mathrm{ml}$ using the diluent.

\section{General procedure}

\section{Multiwavelength regression method}

The absorbance of the synthetic mixtures, standards and samples were measured in the range of 230 $260 \mathrm{~nm}$ at $5 \mathrm{~nm}$ intervals. For the application of the method, the ratio of the synthetic mixture or sample absorbances to that of atorvastatin analytical standard solution at each wavelength was calculated and plotted against the ratio of absorbance values obtained for amlodipine analytical standard solution to the same atorvastatin standard solution used in the first instance. The slope and intercept of the straight line obtained were then used to calculate the concentration of each analyte in the mixture or the sample.

\section{Absorbance factor method}

The absorbance factor was initially calculated from the absorbance values of amlodipine calibration series as the ratio of the absorbance of each solution at $244 \mathrm{~nm}$ to its corresponding absorbance at $365 \mathrm{~nm}$. The average absorbance factor obtained was then used to correct the absorbance of atorvastation by removing the interference due amlodipine at $244 \mathrm{~nm}$. The concentration of each analyte was calculated using its corresponding regression equation.

\section{Results}

Spectral characteristics

UV absorbance spectra of amlodipine $15 \mu \mathrm{g} / \mathrm{mL}$ and atorvastatin $23 \mu \mathrm{g} / \mathrm{mL}$ were recorded over the range of 200-400 nm against the diluent as a blank (Fig. 2). AML showed maximum absorbance at $244 \mathrm{~nm}$ and $365 \mathrm{~nm}$ while AVS showed maximum absorbance at 
Table 1 Amlodipine linearity data (multiwavelength regression method)

\begin{tabular}{llllllll}
\hline Parameter & $\mathbf{2 3 0} \mathbf{n m}$ & $\mathbf{2 3 5} \mathbf{n m}$ & $\mathbf{2 4 0} \mathbf{n m}$ & $\mathbf{2 4 5} \mathbf{n m}$ & $\mathbf{2 5 0} \mathbf{n m}$ & $\mathbf{2 5 5} \mathbf{n m}$ & $\mathbf{2 6 0} \mathbf{n m}$ \\
\hline$b$ & 0.0379 & 0.0447 & 0.0291 & 0.0131 & 0.0057 & 0.0023 & 0.0006 \\
$a$ & 0.0067 & 0.0047 & 0.0018 & 0.0028 & 0.0021 & 0.0011 & 0.005 \\
$r$ & 0.9994 & 0.9995 & 0.9994 & 0.9997 & 0.9998 & 0.9991 & 1.000 \\
$S_{b}$ & 0.0009 & 0.0009 & 0.0007 & 0.0002 & 0.00009 & 0.00007 & 0.00003 \\
$S_{a}$ & 0.0074 & 0.0076 & 0.0056 & 0.001 & 0.0007 & 0.0005 & 0.00006 \\
LOD $(\mu \mathrm{g} / \mathrm{mL})$ & 0.396 & 0.344 & 0.388 & 0.287 & 0.240 & 0.454 & 0.626 \\
LOQ $(\mu \mathrm{g} / \mathrm{mL})$ & 1.199 & 1.042 & 1.176 & 0.869 & 0.727 & 1.376 & 1.897 \\
\hline
\end{tabular}

$b$ slope, $a$ intercept, $r$ correlation coefficient, $S_{b}$ standard deviation of the slope, $S_{a}$ standard deviation of the intercept, $L O D$ limit of detection, $L O Q$ limit of quantitation

Table 2 Atorvastatin linearity data (multiwavelength regression method)

\begin{tabular}{|c|c|c|c|c|c|c|c|}
\hline Parameter & $230 \mathrm{~nm}$ & $235 \mathrm{~nm}$ & $240 \mathrm{~nm}$ & $245 \mathrm{~nm}$ & $250 \mathrm{~nm}$ & $255 \mathrm{~nm}$ & $260 \mathrm{~nm}$ \\
\hline$b$ & 0.0125 & 0.0365 & 0.0365 & 0.0314 & 0.0275 & 0.0229 & 0.0171 \\
\hline$a$ & 0.0021 & -0.0024 & 0.0079 & 0.015 & -0.0086 & 0.0008 & 0.0109 \\
\hline r & 0.9999 & 0.9998 & 0.9999 & 0.9998 & 0.9999 & 0.9998 & 0.9999 \\
\hline$S_{b}$ & 0.00007 & 0.00052 & 0.00038 & 0.00042 & 0.00034 & 0.00031 & 0.00021 \\
\hline$S_{a}$ & 0.0009 & 0.0068 & 0.00491 & 0.0056 & 0.0045 & 0.0042 & 0.0029 \\
\hline $\mathrm{LOD}(\mu \mathrm{g} / \mathrm{mL})$ & 0.236 & 0.595 & 0.436 & 0.571 & 0.523 & 0.579 & 0.536 \\
\hline LOQ ( $\mu \mathrm{g} / \mathrm{mL})$ & 0.717 & 1.804 & 1.321 & 1.730 & 1.585 & 1.755 & 1.623 \\
\hline
\end{tabular}

$b$ slope, $a$ intercept, $r$ correlation coefficient, $S_{b}$ standard deviation of the slope, $S_{a}$ standard deviation of the intercept, $L O D$ limit of detection, $L O Q$ limit of quantitation

$244 \mathrm{~nm}$ and no absorbance at $365 \mathrm{~nm}$; hence, AML can be determined by measuring its absorbance at $365 \mathrm{~nm}$. Absorbance of AVS at $244 \mathrm{~nm}$ can be determined by use of absorbance factor.

For the application of multilinear regression method, absorbance measurements were taken at $10 \mathrm{~nm}$ intervals over the range of $230-260 \mathrm{~nm}$.

\section{Linearity}

Calibration plots at the wavelength selected for each method were linear over the concentration range, $r^{2}>0.99$.

The limit of quantification (LOQ) and limit of detection (LOD) were evaluated from the regression data using the following equations:

$$
\begin{aligned}
& \mathrm{LOQ}=10 * \sigma / \mathrm{S} \\
& \mathrm{LOD}=3.3 * \sigma / \mathrm{S}
\end{aligned}
$$

$\sigma=$ the standard deviation of the response, $S=$ the slope of the calibration curve.

The absorbance factor determined from the regression data was found to be 2.7042 which was then used to remove the interference of amlodipine with absorbance of atorvastatin at $244 \mathrm{~nm}$. Tables 1, 2, 3, 4 summarize the results of regression analysis.
Table 3 Amlodipine linearity data (absorbance factor method)

\begin{tabular}{lcl}
\hline Parameter & $\mathbf{2 4 4} \mathbf{n m}$ & $\mathbf{3 6 5} \mathbf{n m}$ \\
\hline$b$ & 0.0457 & 0.0165 \\
$a$ & -0.00031 & 0.0016 \\
$r$ & 0.9999 & 0.9998 \\
$S_{b}$ & 0.000294 & 0.00027 \\
$S_{a}$ & 0.002104 & 0.00194 \\
$L O D(\mu \mathrm{g} / \mathrm{ml})$ & 0.147 & 0.376 \\
$\mathrm{LOQ}(\mu \mathrm{g} / \mathrm{ml})$ & 0.446 & 1.138 \\
\hline
\end{tabular}

$b$ slope, $a$ intercept, $r$ correlation coefficient, $S_{b}$ standard deviation of the slope $S_{a}$ standard deviation of the intercept, $L O D$ limit of detection, $L O Q$ limit of quantitation

\begin{tabular}{|c|c|}
\hline Parameter & $244 \mathrm{~nm}$ \\
\hline$b$ & 0.0399 \\
\hline$a$ & 0.0046 \\
\hline$r$ & 0.9999 \\
\hline$S_{b}$ & 0.00018 \\
\hline$S_{a}$ & 0.002810 \\
\hline LOD ( $\mu \mathrm{g} / \mathrm{ml})$ & 0.2249 \\
\hline LOQ ( $\mu \mathrm{g} / \mathrm{ml})$ & 0.6815 \\
\hline
\end{tabular}

Table 4 Atorvastatin linearity data (absorbance factor method)

$b$ slope, $a$ intercept, $r$ correlation coefficient, $S_{b}$ standard deviation of the slope, $S_{a}$ standard deviation of the intercept, LOD limit of detection, LOQ limit of quantitation

Recovery 


\section{Multiwavelength regression method}

Samples and standards absorbance measurements were taken several wavelengths. Linear plots were obtained from the ratios of absorbance the two drugs mixture (or the sample) to the absorbance of atorvastatin analytical standard solution versus the ratios of absorbance amlodipine analytical standard solution to that of the same atorvastatin standard analytical solution used earlier. The slopes and intercepts of the linear plot obtained were then used to calculate the concentration of each analyte. The recovery and percent relative standard deviation (RSD\%) were obtained and are summarized in Table 5.

\section{Absorbance factor method}

The interference of amlodipine with the absorbance due to atorvastatin at $244 \mathrm{~nm}$ was removed using the absorbance factor. The concentration of each analyte was then calculated from its corresponding regression equation of absorbance versus concentration, at $244 \mathrm{~nm}$ for atorvastatin and $365 \mathrm{~nm}$ for amlodipine. The recovery and percent relative standard deviation (RSD\%) were obtained and are summarized in Table 6 .

\section{Precision of the proposed methods}

The precision of the proposed methods was studied by analyzing six independent replicate samples from the commercial product on two different days. The data are reported in Tables 7 and 8.

\section{Commercial product analysis}

The percent recoveries and relative standard deviations (\%RSD) obtained by applying the proposed methods to the analysis of independent six replicate samples from the commercial product are reported in Tables 9.

Furthermore, statistical comparison indicated that there is no significant difference between the assay results obtained by the two method as the calculated $t$ values

Table 5 Multiwavelength regression method recovery results

\begin{tabular}{|c|c|c|c|c|c|c|c|}
\hline \multirow[t]{2}{*}{ Mixture no. } & \multirow{2}{*}{$\begin{array}{l}\text { Regression equation } \\
Y=b x+a\end{array}$} & \multicolumn{2}{|c|}{ Amlodipine $(\mu \mathrm{g} / \mathrm{mL})$} & \multirow[t]{2}{*}{$\%$ Content } & \multicolumn{2}{|c|}{ Atorvastatin $(\mu \mathrm{g} / \mathrm{mL})$} & \multirow[t]{2}{*}{$\%$ Content } \\
\hline & & Theoretical & Actual & & Theoretical & Actual & \\
\hline 1 & $\begin{array}{l}0.5987 b+0.5881 \\
(r=0.9999)\end{array}$ & 13.01 & 12.94 & 99.46 & 6.49 & 6.36 & 98.00 \\
\hline 2 & $\begin{array}{l}0.7960 b+0.8059 \\
(r=0.9998)\end{array}$ & 17.33 & 17.21 & 99.31 & 8.65 & 8.72 & 100.81 \\
\hline 3 & $\begin{array}{l}0.9807 b+0.9904 \\
(r=0.9998)\end{array}$ & 21.60 & 20.77 & 98.15 & 10.82 & 10.72 & 99.08 \\
\hline 4 & $\begin{array}{l}0.5915 b+0.7944 \\
(r=0.9999)\end{array}$ & 13.00 & 12.78 & 98.31 & 8.65 & 8.60 & 99.42 \\
\hline 5 & $\begin{array}{l}0.7920 b+0.5932 \\
(r=0.9997)\end{array}$ & 17.30 & 17.12 & 98.96 & 6.49 & 6.42 & 98.92 \\
\hline 6 & $\begin{array}{l}0.5944 b+0.3943 \\
(r=0.9998)\end{array}$ & 13.00 & 12.84 & 98.77 & 4.33 & 4.27 & 98.61 \\
\hline Analytical standard & & $21.62(\mu \mathrm{g} / \mathrm{mL})$ & & & $10.82(\mu \mathrm{g} / \mathrm{mL})$ & & \\
\hline Mean & & 98.83 & & & 99.14 & & \\
\hline RSD (\%) & & 0.53 & & & 0.96 & & \\
\hline
\end{tabular}

Table 6 Absorbance factor method recovery results

\begin{tabular}{|c|c|c|c|c|c|c|}
\hline \multirow[t]{2}{*}{ Mixture no. } & \multicolumn{2}{|c|}{ Amlodipine $(\mu \mathrm{g} / \mathrm{ml})$} & \multirow[t]{2}{*}{$\%$ Content } & \multicolumn{2}{|c|}{ Atorvastatin $(\mu \mathrm{g} / \mathrm{ml})$} & \multirow[t]{2}{*}{$\%$ Content } \\
\hline & Theoretical & Actual & & Theoretical & Actual & \\
\hline 1 & 4.38 & 4.37 & 99.77 & 8.33 & 8.52 & 102.24 \\
\hline 2 & 6.58 & 6.56 & 99.70 & 12.50 & 12.81 & 102.48 \\
\hline 3 & 8.77 & 8.74 & 99.66 & 16.67 & 16.60 & 99.58 \\
\hline 4 & 8.77 & 8.68 & 98.97 & 8.33 & 8.34 & 100.12 \\
\hline 5 & 4.38 & 4.37 & 99.77 & 16.67 & 16.59 & 99.52 \\
\hline 6 & 6.58 & 6.56 & 99.70 & 16.67 & 17.07 & 102.40 \\
\hline Mean & & 99.59 & & 101.06 & & \\
\hline RSD (\%) & & 0.31 & & 1.44 & & \\
\hline
\end{tabular}


Table 7 The precision of the multiwavelength regression method

\begin{tabular}{|c|c|c|c|c|c|}
\hline \multicolumn{2}{|c|}{$\mathrm{AML}(\mu \mathrm{g} / \mathrm{mL})$} & \multirow[t]{2}{*}{$\%$ LC } & \multicolumn{2}{|c|}{ AVS $(\mu \mathrm{g} / \mathrm{mL})$} & \multirow[t]{2}{*}{$\%$ LC } \\
\hline Actual & Found & & Claim & Found & \\
\hline \multicolumn{6}{|c|}{ Repeatability $(n=6)$} \\
\hline 5.02 & 5.00 & 99.60 & 20.10 & 20.29 & 100.97 \\
\hline 4.94 & 4.89 & 98.99 & 19.74 & 19.71 & 99.85 \\
\hline 5.11 & 5.10 & 99.80 & 20.43 & 20.55 & 100.59 \\
\hline 5.01 & 4.98 & 99.40 & 20.02 & 20.30 & 101.40 \\
\hline 4.83 & 4.82 & 99.79 & 19.31 & 19.31 & 100.00 \\
\hline 4.94 & 4.42 & 98.44 & 17.97 & 17.98 & 100.06 \\
\hline Mean & & 99.34 & Mean & & 100.47 \\
\hline RSD\% & & 0.55 & RSD\% & & 0.61 \\
\hline \multicolumn{6}{|c|}{ Intermediate precision $(n=6)$} \\
\hline 5.00 & 5.04 & 100.80 & 20.00 & 20.30 & 101.55 \\
\hline 5.00 & 4.98 & 99.50 & 20.00 & 20.38 & 101.90 \\
\hline 5.00 & 5.04 & 100.84 & 20.00 & 19.97 & 99.90 \\
\hline 4.99 & 4.94 & 98.92 & 19.96 & 20.18 & 101.10 \\
\hline 5.00 & 5.03 & 100.60 & 19.97 & 19.94 & 98.85 \\
\hline 5.00 & 4.93 & 98.68 & 20.00 & 20.36 & 101.85 \\
\hline Mean & & 99.87 & Mean & & 101.03 \\
\hline RSD\% & & 0.98 & RSD\% & & 0.94 \\
\hline
\end{tabular}

Table 8 The precision of the absorbance factor method

\begin{tabular}{|c|c|c|c|c|c|}
\hline \multicolumn{2}{|c|}{$\mathrm{AML}(\mu \mathrm{g} / \mathrm{mL})$} & \multirow[t]{2}{*}{$\%$ Content } & \multicolumn{2}{|c|}{ AVS $(\mu \mathrm{g} / \mathrm{mL})$} & \multirow[t]{2}{*}{$\%$ Content } \\
\hline Actual & Found & & claim & Found & \\
\hline \multicolumn{6}{|c|}{ Repeatability $(n=6)$} \\
\hline 4.99 & 4.92 & 98.50 & 19.99 & 19.89 & 99.96 \\
\hline 4.99 & 4.92 & 98.50 & 19.99 & 19.89 & 99.96 \\
\hline 4.99 & 4.92 & 98.50 & 19.99 & 19.86 & 99.83 \\
\hline 5.00 & 4.97 & 98.49 & 20.00 & 19.83 & 99.13 \\
\hline 5.00 & 4.91 & 99.30 & 20.00 & 19.89 & 99.47 \\
\hline 4.99 & 4.91 & 98.50 & 19.99 & 17.87 & 99.84 \\
\hline Mean & & 98.63 & Mean & & 99.70 \\
\hline RSD\% & & 0.43 & $\mathrm{RSD} \%$ & & 0.34 \\
\hline \multicolumn{6}{|c|}{ Intermediate precision $(n=6)$} \\
\hline 5.00 & 4.97 & 9.48 & 20.00 & 19.90 & 99.50 \\
\hline 4.9 & 4.92 & 100.31 & 19.90 & 19.99 & 100.47 \\
\hline 5.00 & 4.92 & 98.30 & 20.00 & 19.97 & 99.84 \\
\hline 4.99 & 4.97 & 99.68 & 19.90 & 19.95 & 101.10 \\
\hline 4.99 & 5.03 & 100.87 & 19.90 & 19.83 & 98.85 \\
\hline 5.00 & 5.03 & 100.67 & 20.00 & 19.88 & 101.85 \\
\hline Mean & & 99.87 & Mean & & 99.86 \\
\hline RSD\% & & 0.98 & RSD\% & & 0.42 \\
\hline
\end{tabular}

0.91 and 1.13 for amlodipine and atorvastatin, respectively, were less than the tabulated $t$ value 2.23 at $95 \%$ confidence level, and the results are shown in Table 9.
Table 9 Analysis of the commercial product and their statistical comparison

\begin{tabular}{lll}
\hline Parameter & $\begin{array}{l}\text { Multiwavelength } \\
\text { regression method }\end{array}$ & $\begin{array}{l}\text { Absorbance } \\
\text { factor } \\
\text { method }\end{array}$ \\
\hline $\begin{array}{l}\text { Amlodipine }(n=6) \\
\% \mathrm{LC}(\mathrm{RSD} \%)\end{array}$ & $99.34(0.55)$ & $98.63(0.43)$ \\
$\begin{array}{l}\text { Atorvastatin }(n=6) \\
\% \mathrm{LC}(\mathrm{RSD} \%)\end{array}$ & $100.47(0.61)$ & $99.70(0.34)$ \\
$t$ test & AML & 0.91 \\
Calculated $t$ value & AVS & 1.13 \\
$t$ tabulated & & 2.23 \\
\hline
\end{tabular}

\section{Discussion}

The absorbance values of the calibration standards used for the two methods showed good proportionality with the concentrations, the squared correlation coefficients were $>0.99$ and the calibration plots showed small insignificant intercepts in both cases [32].

Good agreement between the theoretical and the actual concentrations of the analytes in the synthetic mixtures was obtained with small relative standard deviation (RSD\%) values $(<2 \%)$, confirming satisfactory recovery by the two methods.

The repeatability and intermediate precision of both methods produced relative standard deviation (RSD\%) values $<2 \%$. Adequate \% recoveries and low \% RSD were obtained when the two proposed method applied to the analysis of the commercial product.

Statistical analysis of the precision data applying student $t$ test confirmed that there was no day to day variation in the results.

The two methods were found to satisfy the requirements of the International Conference on Harmonization (ICH) with regard to linearity, precision and accuracy [33].

Statistical comparison indicated that there is no significant difference between the assay results obtained by the two method as the calculated $t$ values 0.91 and 1.13 for amlodipine and atorvastatin, respectively, were less than the tabulated $t$ value 2.23 at $95 \%$ confidence level [34].

\section{Conclusions}

Simple, accurate, precise and cost effective spectrophotometric methods have been developed and validated for the determination of amlodipine and atorvastatin in combined dosage form. The proposed methods are also having the advantage of using very simple spectrophotometric approaches for the determination of the two drugs 
mixture without prior separation or using sophisticated instruments and software. Either of the two methods can be used with confidence for the analysis of the two drugs mixture since no significant differences in the analytical results were observed between them. The proposed methods are beneficial for poor countries where acquisition of such equipment is not affordable.

\section{Abbreviations}

AML: Amlodipine; AVS: Atorvastatin; \%RSD: Relative standard deviations; LOQ: Limit of quantification; LOD: Limit of detection; $\sigma$ : The standard deviation of the response; S: The slope of the calibration curve; UV: Ultraviolet; ICH: International Conference on Harmonization of registration requirements.

\section{Acknowledgements}

Authors acknowledge the support provided by the staff of Department of Pharmaceutical Chemistry, Faculty of Pharmacy, National Al Eibat UniversitySudan, for the present work.

\section{Authors' contributions}

HF and SE performed the analysis, reported the results and prepared the first draft. The corresponding author revised the calculations and prepared the final manuscript. All authors have read and approved the manuscript.

\section{Funding}

No funding received for this research work.

\section{Availability of data and materials}

All data and materials are available upon request.

\section{Declarations}

Ethics approval and consent to participate

Not applicable.

\section{Consent for publication}

Not applicable as our study does not include patients.

\section{Competing interests}

The authors declare that they have no competing interests.

\section{Author details}

1Department of Pharmaceutical Chemistry, Faculty of Pharmacy, University of Khartoum, P.O. Box 1996, Khartoum, Sudan. ${ }^{2}$ Department of Pharmaceutical Chemistry, Al Ribat National University, Khartoum, Sudan.

Received: 1 July 2021 Accepted: 4 November 2021

Published online: 04 December 2021

\section{References}

1. Sweetman SC (2009) Cardiovascular drugs. In: Martindale, the complete drug reference, 36th edn. Pharmaceutical Press, London, p 1214

2. Sweetman SC (2009) Cardiovascular drugs. In: Martindale, the complete drug reference, 36th edn. Pharmaceutical Press, London, pp. 1218-1219

3. Mc Keage K, Siddiqui MA (2008) Amlodipine/atorvastatin fixed-dose combination: a review of its use in the prevention of cardiovascular disease and in the treatment of hypertension and dyslipidemia. Am J Cardiovasc Drugs 8:51-673. https://doi.org/10.2165/00129784-20080 8010-00007

4. Abdallah OM, Badawey AM (2011) Derivative-ratio spectrophotometric, chemometric and HPLC validated methods for simultaneous determination of amlodipine and atorvastatin in combined dosage form. Int J Ind Chem 2(2):78-85
5. Darwish HW, Hassan SA, Salem MY, El-Zeand BA (2013) Development and validation of $\mathrm{H}$-point standard addition method applied for the analysis of binary mixture of amlodipine and atorvastatin. Int J Pharm Bio Sci 4(2):230-243

6. Sarrafi AHM, Konoz E, Ghiyasvand M (2011) Simultaneous detemination of atorvastatin calcium and amlodipine besylate by spectrophotometry and multivariate calibration methods in pharmaceutical formulations. E J Chem 8(4):1670-1679

7. Silvia I, Klára K, Daniela-Luci M (2013) Simultaneous determination of atorvastatin and amlodipine in industrial tablets by apparent content curve and HPLC methods. Acta Medica Marisiensis 59(1):44-48. https:// doi.org/10.2478/amma-2013-0010

8. Bernard S, Mathew M, Senthilkumar KL, Girija KN (2013) Simultaneous estimation of atorvastatin calcium and amlodipine besylate by UV spectrophotometric method using hydrotropic solubilization. Hygeia J D Med 5(1):105-112

9. Sahu R, Patel BV (2007) Simultaneous spectrophotometric determination of amlodipine besylate and atorvastatin calcium in binary mixture. Indian J Pharm Sci 69(1):110-111. https://doi.org/10.4103/0250-474X.32119

10. Hmadi FA, Am GR (2011) Spectrophotometric determination of atorvastatin and amlodipine by $\mathrm{H}$-point standard addition method with simultaneous addition of both analalytes in nonaqueous solution. Collect Czech Chem Commun 76(3):193-205. https://doi.org/10.1135/cccc2010144

11. Tehrani MB, Shoorvazi M, Souri E (2014) Stability indicating derivative spectrophotometric method for simultaneous determination of amlodipine and atorvastatin in pharmaceutical dosage forms. Res J Pharm Biol Chem Sci 5(3):26-34

12. Darwish HW, Hassan SA, Salem MY, El-Zeany BA (2013) Three different methods for determination of binary mixture of Amlodipine and Atorvastatin using dual wavelength spectrophotometry. Spectrochim Acta Part A Mol Biomol Spectrosc 104:70-76. https://doi.org/10.1016/j.saa.2012.11. 079

13. Sharma K, Sharma Yand Sharma P (2013) Validated method development for estimation of atorvastatin and amlodipine in solid dosage regimens. Int J Res Dev Pharm Life Sci 2(2):344-348

14. Jena A, Madhu M, Latha S (2010) Analytical method development and validation of simultaneous determination of atorvastatin calcium and amlodipine besylate in tabletdosage form by RP-HPLC. IJPSR 1(11):100106. https://doi.org/10.13040/IJPSR.0975-8232.1(11).100-06

15. Hassan SA, Elzanaly ES, Salem MY, EL-Zeany BA (2016) Development and validation of HPLC and CE methods for simultaneous determination of amlodipine and atorvastatin in the presence of their acidic degradation products in tablets. Acta Pharm. 66:479-490. https://doi.org/10.1515/ acph-2016-0040

16. Rao NM, Sankar DG (2016) Development and validation of HPTLC method for the simultaneous estimation of amlodipine besylate and atorvastatin calcium in combined dosage form. Eurasian J Anal Chem 11(3):155-168

17. Hafez HM, Elshanawany AA, Abdelaziz LM, Mohram MS (2014) Development of a stability-indicating HPLC method for simultaneous determination of amlodipine besylate and atorvastatin calcium in tablets. Pharmaceutica Analytica Acta. https://doi.org/10.4172/2153-2435.10003 16

18. Mathew M, Bernard S, Senthil Kumar KL, Girija KN (2014) Development and validation of a high performance thin layer chromatographic method for the simultaneous estimation of atorvastatin calcium and amlodipine besylate as the bulk drugs and in the tablet dosage form. Asian J Pharm Hea Sci 4(2):986-991

19. Eranki RJV, Intil G, Jayaraman V (2013) New stability-indicating method for quantification of impurities in amlodipine and atorvastatin calcium tablets by validated HPLC. Int J Pharm Res Schol 2:458-471

20. Toan PD, Minh PPA, Trucly DT (2016) Novel HPLC-UV method using volatile buffer for simultaneous determination of amlodipine besylate and atorvastatin calcium. Int J Pharm Pharm Sci 8(7):365-368

21. Raja Rajeswari K, Sankar GG, Rao AL, Seshagirirao JVLN (2015) RP-HPLC Method for the simultaneous determination of atorvastatin and amlodipine in tablet dosage form. Indian J Pharm Sci 6(10):1-7. https://doi.org/ 10.4103/0250-474X.25738

22. Moussa BA, El-Zaher A, Mahrouse MA, Ahmed MS (2013) Simultaneous determination of amlodipine besylate and atorvastatin calcium in binary 
mixture by spectrofluorimetry and HPLC coupled with fluorescence detection. Anal Chem Insights 8:107-115. https://doi.org/10.4137/ACI. S12921

23. Ibrahim N, Rizk M, Ibrahim A, Tawakkol S, Ali I (2014) Simultaneous determination of amlodipine besylate and atorvastatin calcium by using spectrophotometric method with multivariate calibration and HPLC method implementing "Design of Experiment." Int J Pharm Pharm Sci 6(1):419-425

24. Ahmed M, Alshabrawy A, Nageh A (2016) UPLC-MS/MS method for kinetic studies and simultaneous determination of amlodipine and atorvastatin in bulk, and their combined dosage form. Anal Chem Ind J 16(14):102-115

25. Dogan-Topal B, Bozal B, Demircigil BT, Uslu B, Ozkan SA (2009) Electroanalytical studies and simultaneous determination of amlodipine besylate and atorvastatine calcium in binary mixtures using first derivative of the ratio-voltammetric methods. Electroanalysis 21(22):2427-2439. https:// doi.org/10.1002/elan.200904689

26. Rebech I, Salamanca-Neto CAR, Scremin J, Sartori ER (2017) Simultaneous voltammetric determination of amlodipine andatorvastatin on anodically pretreated boron-doped diamond electrode orbital. Electron J Chem 9(4):225-233. https://doi.org/10.17807/orbital.v9i4.973

27. Mircia E, Balaci T, Hancu G, Ion V, Carje A (2016) Simultaneous determination of amlodipine and atorvastatin by capillary electrophoresis from fixed pharmaceutical formulations. Farmacia 64(3):398-402

28. Al-Rasoul B, Elsamani T (2016) Validated RP- HPLC method for the simultaneous determination of amlodipine besylate and atorvastatin calcium in bulk and pharmaceutical formulation. Int J Res Pharm Chem 6(4):816-825

29. Abu Reid IO, Mohamed ME (2019) Chemometric simultaneous determination of atorvastatin and amlodipine in bulk and tablets. Int J Pharm Chem 5(4):42-47. https://doi.org/10.11648/j.ijpc.20190504.12

30. Blanco M, Runiaga H, Maspoch S, Tarfn P (1989) A simple method for spectrophotometric determination of two-components with overlapped spectra. J Chem Educ 66(2):178-180. https://doi.org/10.1021/ed066p178

31. Patel CV, Khandhar AP, Captain AD, Patel KT (2007) Validated absorption factor spectrophotometric and reversed phase high performance liquid chromatography methods for the determination of ramipril and omlesartan medoxomil in pharmaceutical formulations. Euroasian J Anal Chem 2(3):159-171

32. Lotfy HM, Fayez YM, Michael AM, Nessim CK (2016) Simultaneous determination of mebeverine hydrochloride and chlordiazepoxide in their binary mixture using novel univariate spectrophotometric methods via different manipulation pathways. Spectrochim Acta A Mol Biomol Spectrosc 155:11-20

33. ICH (2005) ICH topic Q2 (R1) validation of analytical procedure: text and methodology

34. Miller JC, Miller JN (2005) Statistics and chemometrics for analytical chemistry, 5th edn. Pearson Education Limited, p 41

\section{Publisher's Note}

Springer Nature remains neutral with regard to jurisdictional claims in published maps and institutional affiliations.

\section{Submit your manuscript to a SpringerOpen ${ }^{\circ}$ journal and benefit from:}

- Convenient online submission

- Rigorous peer review

- Open access: articles freely available online

- High visibility within the field

- Retaining the copyright to your article

Submit your next manuscript at $\boldsymbol{\nabla}$ springeropen.com 